\title{
Türkiye’de Kredi Kartı Kullanımının Para Politikasındaki Rolü ve Etkileri
}

Esra KABAKLARLI, Department of Economics, Faculty of Economics and Administrative Sciences, Selcuk University, Turkey; e-mail: etalasli@selcuk.edu.tr

\section{The Role and the Effect of Credit Cards Usage on Monetary Policy in Turkey}

\begin{abstract}
In this study, the role and effect of credit card usage which has increased by the years in terms of volume of credit card transactions and number of users through the monetary transmission policy is investigated. The monetary transmission policy which is used by central banks to reach the inflation and financial stability targets through money policy tools is discussed recently. Credit cards usage which belongs to credit channel in the monetary transmission mechanism, is deployed to see effects on monetary policy and the relationship between the economic growth, inflation and interest rates variables are analyzed by using VAR (Vector Autoregression) model for monthly data over the period 2005-2014 in Turkish economy.
\end{abstract}

\section{Keywords $\quad$ : Monetary Policy, Credit Cards, VAR Analysis.}

JEL Classification Codes : C32, E44, E50.

$\ddot{\mathbf{O} z}$

Bu çalışmada Türkiye'de yıllar itibari ile artan işlem hacmi ve kullanıcı sayısına sahip kredi kartlarının parasal aktarım mekanizması aracılığı ile para politikasındaki rolü ve etkisi araştırılmaktadır. Merkez bankasının enflasyon ve finansal istikrar hedefine ulaşmakta kullandığı para politikası araçları ile ekonomiyi hangi kanallardan ve nasıl etkileyeceği hususlarını içeren "parasal aktarım mekanizmaları " son dönemde sıkça tartışılmaktadır. Parasal aktarım mekanizmalarından kredi kanalı içerisinde yer alan kredi kartı kullanımının, VAR (Vektör Otoregresif) modeli kullanılarak; para politikasına etkileri ile büyüme, enflasyon ve faiz oranı gibi değişkenlerle arasındaki ilişki, Türkiye ekonomisi için 2005-2014 yıllarına ait aylık veriler aracılığıyla incelenmiştir.

Anahtar Sözcükler $\quad$ : $\quad$ Para Politikası, Kredi Kartları, VAR Analizi. 


\section{Giriş}

Günümüz ekonomilerinde nakit ile ödemenin yerini kredi kartları alırken, bunun da gelecek yıllarda daha çok akıllı telefonlarla, mobil ödemeler sayesinde gerçekleşeceği öngörülmektedir. Artık kredi kartına fiziksel olarak gerek duyulmaksızın dijital cüzdanlarla tabletten veya akıllı telefonlardan ödeme yapılması mümkündür. Teknolojik gelişmeler ile birlikte toplam tüketim, paranın dolaşım hızı gibi büyüklüklerde kolayca değişebilmektedir.

Çalışmanın amacı, günümüzde yaygın kullanımı olan kredi kartlarının, parasal aktarım mekanizması aracılığı ile para politikasındaki rolü ve etkinliğinin Türkiye ekonomisi için araştırılmasıdır. Bu amaçla yazılan makaleleri incelediğimizde eski FED başkanı Ben S. Bernanke'nin önemli çalışmaları referans olarak sıkça kullanılmaktadır. Bernanke \& Gertler, 1995) konut piyasasının para politikasındaki değişime çabuk tepki verdiğini ancak para politikasının uzun dönem reel faiz oranları üzerinde sınırlı, kontrollü bir etkisinin bulunduğunu belirtmiştir. Berrnanke ve Blinder (1992) kredi kanallarının işleyiş mekanizmasını inceledikleri ünlü çalışmalarında VAR analizi ile 1959-1979 dönemi için FED faiz oranı, işsizlik oranı, tüketici fiyat endeksi, banka bilançolarından elde edilen mevduat, kredi ve menkul kıymetler kalemi verilerini aylık olarak kullanmışlardır. Parasal büyüklüklerin reel ekonomiyi etkileme gücü araştırılmıştır. Çalışmanın sonuçlarına göre; nominal faiz oranları reel ekonominin içinde yer alan değişkenlerin tahmininde önemli ve yol gösterici bir role sahiptir. S1kı para politikası uygulamasının hemen akabinde mevduat hacmi azalır ve daraltıcı etkisi zirveye 9 ay içinde ulaşır. Mevduatlardaki düşme kredi hacmini daraltırken, menkul kıymetlerdeki azalma iki yıl içinde giderilir ve ilk seviyeler yakalanır. İşsizlik oranı, FED faiz oranlarındaki bir standart sapmalık şoktan 9 ay sonra yükselirken iki yıl içinde etkisi zirveye ulaşır. Sıkı para politikası sonucunda bankalar ellerindeki nominal değeri düşen menkul kıymetleri elden çıkarır ve verdikleri kredi miktarını azalmazlarken süresi dolan kredileri yenilememeleri sonucunda reel ekonomide bir yavaşlama beklenebilir.

Türkiye'de parasal aktarım mekanizmasının içinde yer alan kredi kanalı ve kredi kartlarını inceleyen çalışmalar içinde Yılmazkuday (2011), 2002-2009 dönemini kapsayan; sanayi üretim endeksi (GSYH yerine), reel kredi kartı kullanım oranı (toplam kredi kartı kullanımı/ TÜFE), bankalar arası gecelik faiz oranı, tüketici fiyat endeksi, döviz kuru (Euro / TL kuru) gibi değişkenleri aylık verilerle, VAR modeli kullanarak değerlendirmiştir. Çalışmanın sonuçlarına göre; kredi kartı kullanımı, enflasyon oranları üzerinde zamanla artan bir etkiye sahiptir ve para politikası uygulamalarında politika yapıcılar tarafından, kredi kanalı içinde daha fazla önemsenmelidir.

Karpuz (2012), Türkiye için kredi kartı kullanımının yoğunluğuna bağlı olarak 2001-2011 yıllarını iki ayrı döneme bölmüş ve her iki dönem için oluşturulan VAR modeli 
sonucunda elde edilen etki- tepki fonksiyonlarını incelenmiştir. Etki- tepki fonksiyonları sonucunda, kredi kartlarının ekonomideki yaygınlığının artmasının, uygulanan para politikası kapsamında bankalarca kullandırılan kredi miktarının artırıldığı ya da azaltıldığı (daraltıcı ya da genişletici para politikalarına bağlı olarak) durumda, Merkez Bankasının politikalarının daha gecikmeli olarak sonuç vermesine neden olabileceği tespit edilmiştir. Diğer bir tespit ise; Türkiye'de kredi kanalının fiyatlar genel seviyesi için beklendiği şekilde çalışmadığ 1 , GSYH içinse kısa süreli de olsa beklendiği gibi çalıştığı durumudur. Genişletici para politikaları sonucunda düşen faiz oranlarına paralel olarak, kullandırılan kredi miktarının artması ve artan krediler sonucunda da GSYH'de kısa süreli bir artış görülmesi beklenmektedir.

\section{Parasal Aktarım Mekanizması}

Hükümetler ve Merkez Bankaları tarafından yürütülen para politikalarının reel ekonomiyi hangi boyutlarda ve hangi kanallarla etkilediği parasal aktarım mekanizmasının konusunu teşkil etmektedir. Para politikasının toplam talep üzerindeki güçlü etkisi bilinmesine rağmen, merkez bankalarının aksiyonları, toplam arzı sınırlı da olsa etkileyebilmektedir. Literatürde parasal aktarım mekanizmaları için farklı sınıflandırmalar yer alsa da bahsedilen başlıca kanallar; faiz kanalı, kredi kanalı, döviz kuru kanalı, hisse fiyatları kanalı ve bekleyişler kanalı olarak sıralanabilir (Taylor, 1995; Mishkin, 1996).

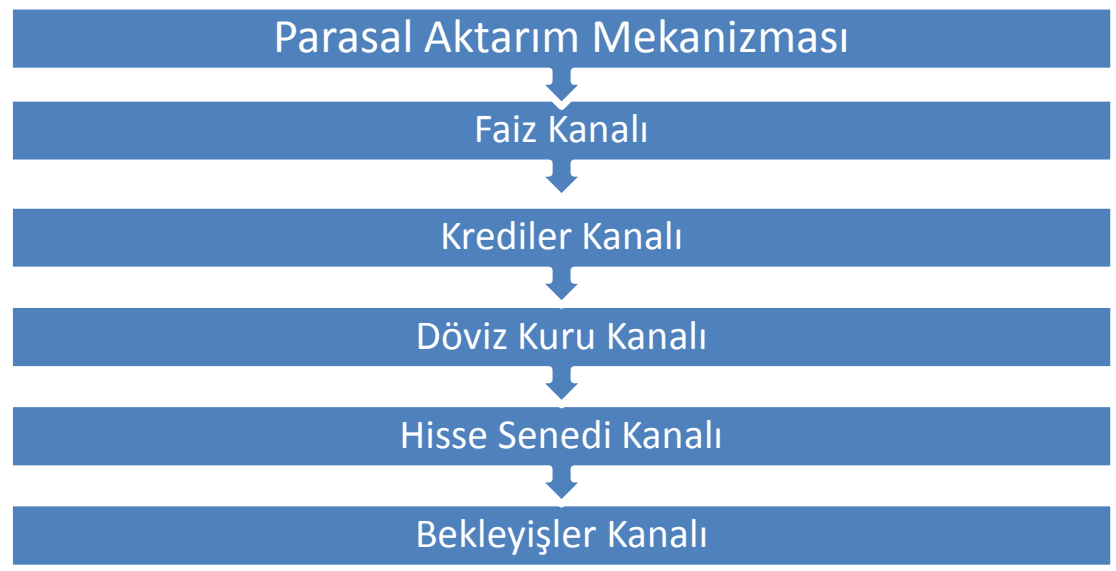

Merkez bankası tarafından gerçekleştirilen ve kısa vadeli faiz oranlarını etkileyecek para politikası aksiyonları reel döviz kurunu ve uzun vadeli faiz oranlarını etkilemektedir. Reel döviz kurundaki değişimler kısa dönemde reel net ihracat, reel 
tüketimler, enflasyon, reel yatırımlar ve reel GSYH üzerinde etkili olabilmektedir (Taylor, 1995: 14).

Geleneksel Keynesyen görüşe göre; IS-LM modeli, parasal aktarım mekanizmasının faiz kanalı ile işleyiş̧ini açık bir şekilde özetlemektedir.

$$
\boldsymbol{M} \uparrow \rightarrow \boldsymbol{i}, \downarrow \rightarrow I \uparrow \rightarrow \boldsymbol{Y} \uparrow
$$

$\mathrm{M} \uparrow$ ile gösterilen genişletici para politikası sonrasında reel faiz oranlarındaki düşüş $(i, \downarrow)$, sermayenin maliyetini düşürerek yatırımların artmasını (I $\uparrow$ ) sağlayacaktır. Artan yatırımlar toplam talebin ve çıktının artmasına $(\mathrm{Y} \uparrow$ ) yardımcı olur (Mishkin, 1996: 2).

Tüketim ve yatırım kararlarını faiz oranlarının belirlediği ampirik olarak pek çok çalışmada test edilerek doğrulanmıştır. Bu açıdan para politikalarında gerçekleşen bir aksiyon ve faiz oranlarındaki değişim toplam tüketim harcamalarını, kredileri ve yatırımları etkiler.

Aktarım mekanizması içinde kredi kanalının çalışmasını sağlayan banka borçlanma kanalı ile bilanço kanalıdır. Genişletici para politikası sonrasında bankaların rezervleri ve mevduatları artar. $\mathrm{Bu}$ şekilde bankaların borç verebilme imkânları yeni kredileri artış gösterir. Kredi şartlarını yerine getirebilen firmaların yatırımları ve dolaylı olarak reel GSYH artış gösterir. Bilanço kanalına göre ise Merkez Bankası tarafindan uygulanan sıkı para politikası ile yükselen faizler borçluları olumsuz etkileyerek ödenecek dönem sonu faiz harcamamalarını artırır. Diğer taraftan artan faizler, sabit faizli tahvil ve bonoların nominal değerini düşürür. $\mathrm{Bu}$ durum banka ve hane halkının finansal açıdan ellerinde bulunan menkul kıymetlerin değerinin düşmesine ve daha az harcamalarına yol açar (Bernanke \& Gertler, 1995: 36-40).

\section{$M \uparrow \rightarrow$ BankaMevduatlar $\uparrow \rightarrow$ Banka Kredileri $\uparrow \rightarrow I \uparrow \rightarrow Y \uparrow$}

Genişletici para politikasının küçük işletmelerin harcamaları ve yatırımları üzerindeki refah etkisi büyük işletmelere göre daha fazladır. Büyük işletmeler bankaların aracılığı olmadan da bono, tahvil ve hisse senedi arzı yoluyla sermaye piyasalarına direkt ulaşabilirken küçük işletmeler banka kredilerine daha çok bankalar aracılığı ile ulaşırlar (Mishkin, 1996: 9).

Parasal aktarım mekanizması içinde döviz kuru kanalının etkinliği ülkenin sermaye hareketlerine açıklığına bağlıdır. Örneğin faiz oranındaki artış ülke parasının değer kazanmasına ve ithal malların ucuzlamasıyla beraber enflasyonun düşmesine yol açacaktır. 
Sermaye hareketlerine açık olan küçük ve esnek döviz kuruna sahip bir ülkede döviz kuru kanalı önemli bir rol üstlenebilir (Taylor, 1995: 16).

$$
\mathbf{M} \uparrow \rightarrow i, \downarrow \rightarrow E \downarrow \rightarrow N E \uparrow \rightarrow Y \uparrow
$$

$\mathrm{M} \uparrow$ ile gösterilen genişletici para politikası sonrasında reel faiz oranlarındaki düşüş $(i, \downarrow)$, ülke parasını değersizleştirerek, net ihracatın artmasını (NE $\uparrow$ ) sağlayacaktır. Artan ihracat, toplam talebin ve çıktının artmasına (Y $\uparrow$ ) yardımıı olur (Mishkin, 1996: 3).

Hisse senedi kanall; Tobin'in q teorisine göre; para politikasındaki gelişmeler hisse senedi değerini değiştirerek ekonomiyi etkilemektedir. Tobin işletmelerin piyasa değerlerini sermaye maliyetlerine bölerek q olarak tanımlamıştır. q'nun yükselmesi şirket değerlerinin sermaye maliyetlerine oranla yüksek olmasını ve yatırımların artmasını sağlayabilir. Böylece işletmeler daha az maliyetle yatırım yaparak yüksek değerden yeni hisseler arz edebilirler. Tobin'in q teoisi hisse senedi ve yatırımlar arasındaki ilişkiyi özetlerken, parasal aktarım mekanizması, parasal genişlemelerin hisse senedi talebini ve dolaylı olarak fiyatlarını artması sonucu gerçekleşmektedir (Poddar vd., 2006: 6).

$$
\mathbf{M} \uparrow \rightarrow \boldsymbol{P}_{\boldsymbol{e}} \uparrow \rightarrow \boldsymbol{q} \uparrow \boldsymbol{I} \uparrow \rightarrow \boldsymbol{Y} \uparrow
$$

Artan para arzı ile düşen faizler bonoları hisse senedine oranla daha az cazip kılarken hisse talebi artar ve fiyatı yükselir. Bu da q'nu yükselmesine yatırımların ve reel çıktının artışına yol açar.

Bekleyişler kanal, parasal şokların hane halkının gelecekle ilgili verdiği ekonomik kararları ve enflasyon algısını değiştirmesine başı olarak çalışır. Enflasyon oranı için bireylerin ve kurumların beklentileri faiz oranları, döviz kuru, ücretler, toplam talep ve yurt içi fiyatlar üzerinde etkili olur (Çevik \& Teksöz, 2012).

\section{Türkiye'de Kredi Kartlarının Parasal Aktarım Mekanizmasındaki Rolü}

Kredi kartlarının taksit özelliği, borç erteleme, bonus ya da hediye puanlar, mil gibi kullanım avantajları faiz oranlarına duyarlı tüketim harcamalarının faiz esnekliğini etkileyebilmektedir (Karpuz, 2012: 167). Kredi kartlarının parasal aktarım mekanizmalarından kredi kanalı içinde yer aldığını düşündügümüzde, hane halkının kredi imkânları içinde yer alan, kredi kartı kullanım oranları para politikasının etkinliğini değiştirebilmektedir.

Türkiye'de 1980'li yıllardan itibaren kullanılmaya başlanan plastik kredi kartları hızlı gelişim göstermiştir. Kartlı ödeme sistemlerine kolay adapte olan Türk halkı, hem 
banka kartı sayısında, hem de kredi kartı sayısında Avrupa ülkeleri arasında ikinci sıraya yükselmiştir (BKM, 2013: 4). Türkiye'de bankacılık sisteminin dünyadaki öncü konumu ve kartlı ödeme sistemindeki gelişmeler düşünüldügüünde, kredi kartlarının parasal aktarım mekanizmasındaki rolü daha fazla etkinleşmiş ve para politikası uygulamalarında dikkat edilmesi gereken bir etken haline gelmiştir.

Tablo: 1

Türkiye'de Artan Kredi Kartı Kullanımı (2009-2014)

\begin{tabular}{|l|c|c|c|c|c|}
\hline & $\begin{array}{c}\text { Kredi Kartı } \\
\text { Sayısı }\end{array}$ & $\begin{array}{c}\text { Toplam } \\
\text { İşlem Adedi }\end{array}$ & $\begin{array}{c}\text { Toplam İşlem } \\
\text { Tutarı } \\
\text { (Milyon TL) }\end{array}$ & $\begin{array}{c}\text { İnternetten Yapılan } \\
\text { Kartlı Ödeme } \\
\text { İşlem Adedi }\end{array}$ & $\begin{array}{c}\text { İnternetten Yapılan } \\
\text { Kartlı Ödeme İşlem Tutarı } \\
\text { (Milyon TL) }\end{array}$ \\
\hline $\mathbf{2 0 0 9}$ & 44.392 .614 & 1.747 .831 .113 & $183.429,89$ & $57,227,057$ & $9,109.05$ \\
\hline $\mathbf{2 0 1 0}$ & 46.956 .124 & 1.946 .634 .407 & $213.701,6$ & $75,414,419$ & $12,880.24$ \\
\hline $\mathbf{2 0 1 1}$ & 51.360 .809 & 2.166 .288 .480 & $265.336,83$ & $102,277,215$ & $18,740.92$ \\
\hline $\mathbf{2 0 1 2}$ & 54.342 .148 & 2.408 .539 .092 & $331.815,9$ & $133,004,366$ & $25,178.32$ \\
\hline $\mathbf{2 0 1 3}$ & 56.835 .221 & 2.610 .874 .305 & $388.516,13$ & 168.061 .356 & $34.606,04$ \\
\hline $\mathbf{2 0 1 4} *$ & 57.346 .935 & 1.559 .913 .883 & $241.178,56$ & 110.235 .168 & $24.201,28$ \\
\hline
\end{tabular}

Kaynak: Bankalararası Kart Merkezi (BKM), Dönemsel Bilgiler, <http://www.bkm.com.tr/donemsel-bilgiler.bkm>, 03.09.2014.

*2014 Temmuz ayı verileri, kredi kartı alışverişte kullanımı göstermektedir.

Bankacılık Denetleme ve Düzenleme Kurulu (BDDK), Şubat 2014 tarihinde yürürlüğe giren taksit düzenlemesi ile kredi kartlarında taksit süresini 9 ay ile sınırlandırmış ayrıca telekomünikasyon ve kuyumculuk harcamalarında taksitlendirmeyi kaldırmıştır (BDDK, 2014). Bu değişiklikle hükümet kredi kartlarının borç çevirmedeki bilinçsiz kullanımının önüne geçmeyi ve para politikaları uygulamalarındaki etkinliğini sınırlandırmayı hedeflemektedir. Uygulama etkisini çabuk göstermiş ve Haziran ayında bir önceki yılın aynı ayına kıyasla taksitli ödemeler \%10 azalmıştır. Ancak hane halkı ve işyerleri uygulamanın alternatifine çabuk uyum gösterirken, taksitlendirmede sektör sınırlandırmasının ticari kartlarda kalkması ile Tablo 2'deki verilerden de görüldüğg̈ gibi, ticari kart kullanımını artırmıştır (BKM, 2014: 2).

Tablo: 2

Kredi Kartları ile Taksitli Ödeme Tutarı (Milyar TL) ve Ticari Kredi Kartlarının Payı

\begin{tabular}{|l|c|c|c|}
\hline & 2013 Haziran & 2014 Haziran & Değişim \\
\hline Toplam Kredi Kartı Taksitli Ödeme Tutarı (Milyar TL) & 9,3 & 8,3 & $-10 \%$ \\
\hline Ticari Kredi Kartı Taksitli Ödeme Tutarı (Milyar TL) & 1,1 & 1,6 & $43 \%$ \\
\hline Ticari Kredi Kartlarının Toplam İçindeki Payı & $12 \%$ & $19 \%$ & \multicolumn{2}{|c}{} \\
\cline { 1 - 3 } & &
\end{tabular}

Kaynak: BKM, Aylı Bülten, 2014 Temmuz, <http://www.bkm.com.tr/Upload/basin/BKM-Aylik-Bulten201406.pdf>, 03.09.2014. 


\section{Veri Seti ve Yöntem}

Parasal aktarım mekanizması içinde kredi kanalını inceleyen literatüre baktığımızda farklı değişkenler kullanılmakla beraber reel ekonomi için GSYİH değişkeni, para politikası için para arzı (M1) ve fiyatlar genel seviyesi için ise Tüketici Fiyat Endeksinin kullanıldığı görülmektedir. İncelenen literatür sonrasında çalışmada kullanılan veriler aşağıdaki tabloda sıralanmıştır.

Tablo: 3

\section{VAR Modeli İçerisinde Kullanılan Değişkenler}

\begin{tabular}{|l|l|}
\hline $\begin{array}{l}\text { Model } \\
\text { İçerisindeki } \\
\text { Sembol }\end{array}$ & Veriye Ait Bilgi \\
\hline Lsanayi & $\begin{array}{l}\text { Sanayi Üretim Endeksi, mevsim ve takvim etkisinden arındırılmış (2010=100), logaritması } \\
\text { alınmış (GSYH değişkenini temsilen yer almaktadır) }\end{array}$ \\
\hline Lrkart & $\begin{array}{l}\text { Yerli ve yabancı kartlarla yurt içinde gerçekleşen reel kredi kartı kullanım tutarı. } \\
\text { Mevsimsellikten arındırılmış, tüketici fiyat endeksi ile reel değerlere dönüştürülmüş ve } \\
\text { logaritması alınmış. }\end{array}$ \\
\hline Tüfe & Tüketici Fiyat Endeksinde meydana gelen aylık \% değişim, mevsimsellikten arındırılmış. \\
\hline M1 & Dar para arzındaki aylık \% değişim \\
\hline Lrfaiz & $\begin{array}{l}\text { Bankalarca Açılan Kredilere Uygulanan Ağırlıklı Ortalama Faiz Oranları, ihtiyaç kredisi } \\
\text { faiz oranı, tüketici fiyat endeksi ile reel değerlere dönüştürülmüş, logaritması alınmış. }\end{array}$ \\
\hline
\end{tabular}

GSYH serilerinin çeyrek dönemler şeklinde hesaplanmasından dolayı bu serilerin yerine geçebilecek aylık hesaplanan, öncü nitelikteki sanayi üretim endeksi serilerine yer verilmiştir. Sanayi üretim endeksi, inşaat sektörü ve bazı sektörler dâhil edilmeden madencilik, imalat sanayi ve enerji sektörünün, alt ana sektörleri ayrıntısında hesaplanmaktadır. Ekonomideki iş çevrimlerinin göstergesidir. Sanayide oluşan katma değer üzerinden hesaplamalarda bulunur. GSYİH serisi ile paralel hareket eder ve en önemli bileşenlerindendir (Mitchell vd., 2012: 545).

Model içerisinde yer alan kredi kartı kullanım tutarı ile TÜFE değişkenlerinin grafikleri incelendiğinde gösterdiği mevsimsel düzenli hareketler nedeniyle Tramo/Seats yöntemiyle mevsimsellikten arındırılmıştır. Sanayi Üretim endeksi, düzey verileri mevsim ve takvim etkisinden arındırılarak yayınlandığı için tekrar bir uygulama yapılmamıştır. 
Şekil: $1 \& 2$

Tüketici Fiyat Endeksi ve Sanayi Üretim Endeksi

TUFE

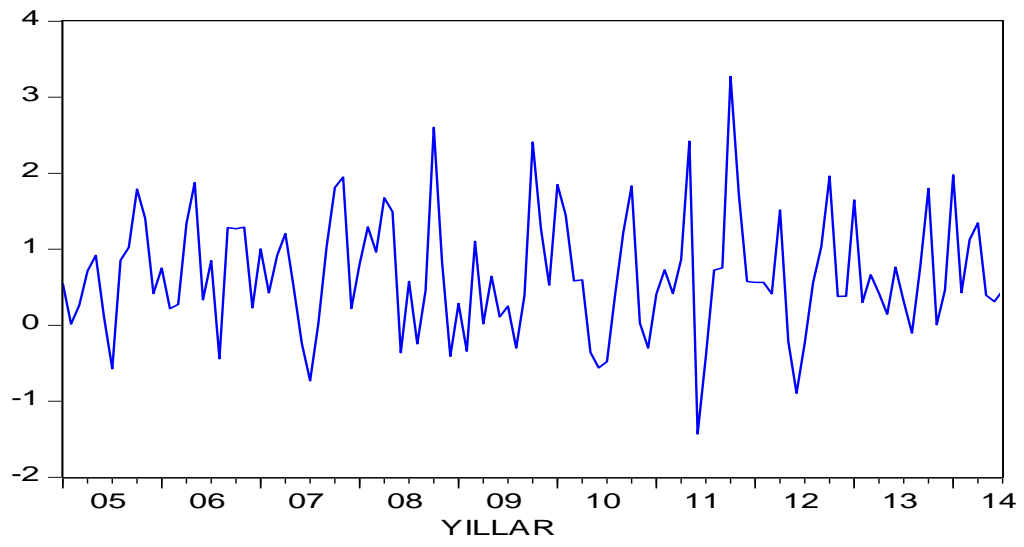

Kaynak: TCMB, Istatistiki Veriler, Fiyat Endeksleri.

Sanayi Üretim Endeksi

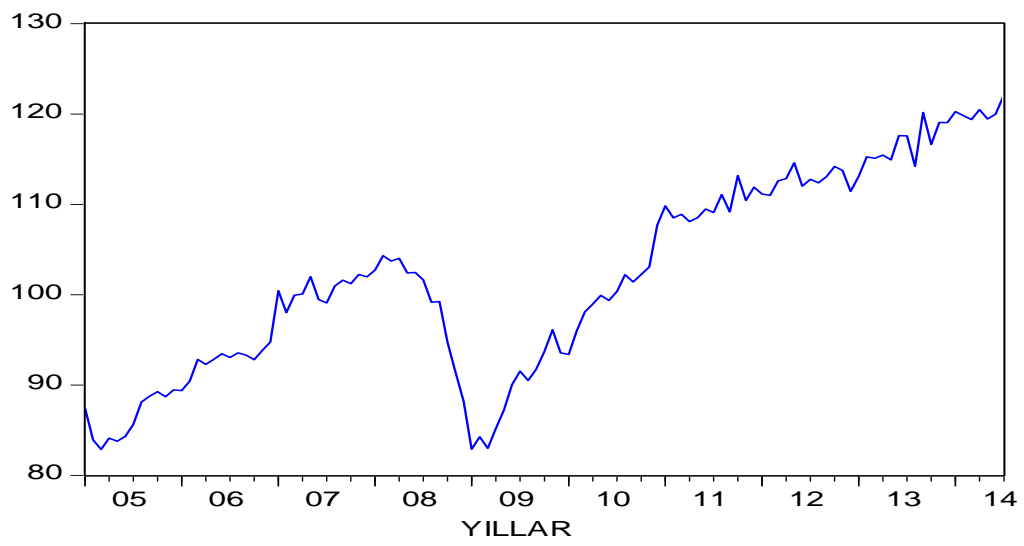

Kaynak: TUiK, İstatistik Göstergeler. 
Türkiye'nin sanayi üretiminin global krizin başlamasıyla birlikte, 2009 y1lı ilk çeyreğinde resesyona girdiği ve üretimin keskin bir şekilde 2008 yılı sonlarında düştüğü gözlemlenmektedir. Toparlanma ardından üretim 2011 yılında tekrar yükselişe geçmiştir.

Şekil: 3

\section{Reel Kredi Kartı Kullanım Tutarı}

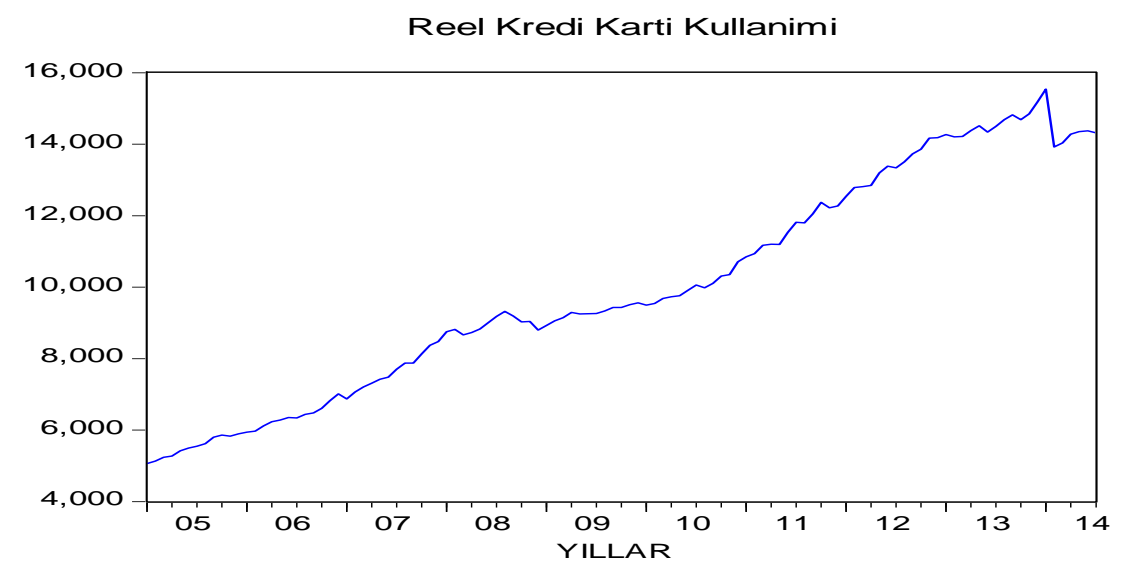

Kaynak: Bankalararası Kart Merkezi (BKM), Yerli ve Yurt içi Kredi Kartlarının Kullanım Tutarı.

Reel kredi kartı kullanım tutarı grafiğe göre: 2005-2014 yılları arasında 2008 yılına kadar hızlı bir yükseliş göstermiş ardından 2008 sonlarında yaşanan global krizin etkisiyle düşüş ve 2010 yılı başlarında tekrar eski seviye yakalanıp tekrar bir yükseliş gözlenmiş̧ir.

Kredi kartı kullanımında diğer bir düşüş ise BDDK'nın para politikasının etkinliğini artırmak amacıyla 2014 Şubat ayında yürürlüğe soktuğu bazı sektörlere taksit uygulamasını kaldırması nedeniyle yaşanmıştır. 
Şekil: 4

\section{Bankalarca Açılan Kredilere Uygulanan Ağırıkıı Ortalama Faiz Oranları}

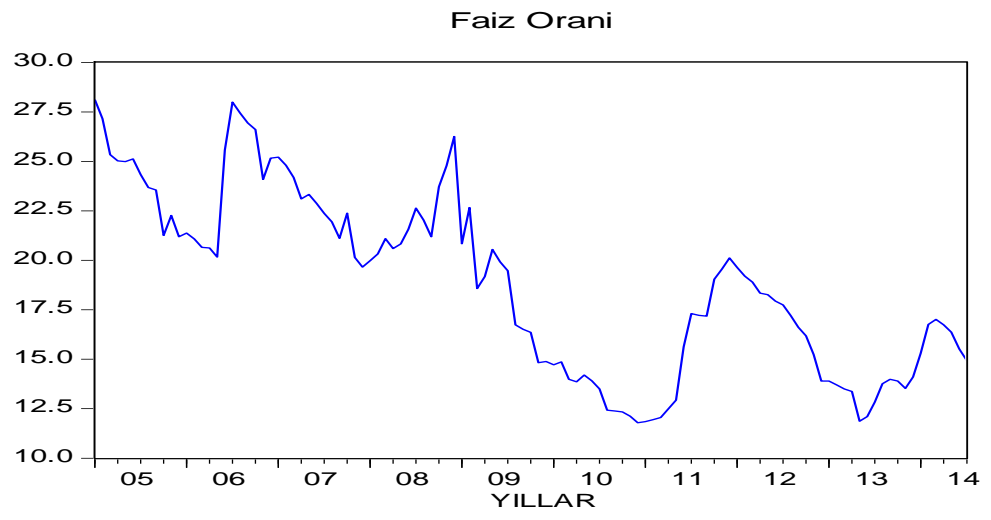

Kaynak: TCMB, İstatistiki Veriler, Haftallk Para Ve Banka İstatistikleri, İhtiyaç Kredisi (TL Üzerinden Açllan) Faiz Orani.

Şekil 4'de yer alan faiz oranları grafiği incelendiğinde 2005-2009 yılları arasında ara ara çıkıp yükselen faiz oranları özellikle FED'in global krizin olumsuz etkilerini bertaraf etmek için uyguladığı genişletici para politikası ile beraber dünyada düşen faiz oranlarının etkisiyle 2009 yılından itibaren düşüşe geçmiştir. 2011 yllının başlarındaki dip seviyenin ardından bir yükseliş yaşandığı ve 2012 yılının ortalarında tekrar keskin bir düşüşün yaşandığı gözlemlenmektedir.

Kredi kartı kullanımının parasal aktarım mekanizmasızındaki rolü için kullanılan en popüler yöntem VAR modelinin kurulmasıdır. VAR modelinin, makroekonomik değişkenler arasındaki ilişkinin incelenmesi ve şokların değişkenlere olan dinamik etkisinin ölçülmesinde, değişkenler için içsel ve dışsal ayrımı gözetmeksizin kullanılabilmesi önemli bir avantajdır (Sims, 1980).

"k" değiş̧kenli bir VAR modelinde her bir değişkenin sırayla bağımlı değişken olduğu k sayıda denklem bulunmaktadır. Her bir denklemdeki gecikme sayısı da p'ye eşittir. “ $\mathrm{k}$ "değişkenli ve p gecikmeli böyle bir denklem sistemine $\operatorname{VAR}(\mathrm{p})$ denir ve aşağıdaki, şekilde gösterilir (Lütkepohl, 2004: 88). 


$$
\begin{gathered}
Y_{1 t}=a_{10}+\sum_{j=1}^{p} B_{1 p} Y_{1 t-p}+\cdots \sum_{j=1}^{p} \gamma_{1 p} Y_{k t-p}+\mu_{1 t} \\
\vdots \\
Y_{k t}=a_{k 0}+\sum_{j=1}^{p} B_{k p} Y_{1 t-p}+\cdots \sum_{j=1}^{p} \gamma_{k p} Y_{k t-p}+\mu_{k t} \\
{\left[\begin{array}{c}
\Delta G S Y H \\
M 1 \\
\Delta F A \dot{\mathrm{I} Z} Z \\
T U F E
\end{array}\right]=\left[\begin{array}{ccc}
A_{11} & \cdots & A_{14} \\
\vdots & \ddots & \vdots \\
A_{41} & \cdots & A_{44}
\end{array}\right]\left[\begin{array}{c}
\Delta G S Y H_{t-1} \\
M 1_{t-1} \\
\Delta F A \mathrm{I} Z_{t-1} \\
T U F E_{t-1}
\end{array}\right]+\left[\begin{array}{c}
c_{1} \text { Kart }_{t-1} \\
c_{2} \operatorname{Kart}_{t-1} \\
c_{3} \operatorname{Kart}_{t-1} \\
c_{41} \text { Kart }_{t-1}
\end{array}\right]+\ldots .+\left[\begin{array}{c}
e_{1 t} \\
e_{2 t} \\
e_{3 t} \\
e_{4 t}
\end{array}\right]}
\end{gathered}
$$

1 numaralı formülde VAR modelinde değişkenler ve gecikmeli değerleri arasındaki ilişki eşanlı denklem sitemi içinde gösterilmiş̧ir. 2 numaralı formülde VAR modeli ve makalede kullanılan değişkenler: GSYH (Sanayi indeksi ile hesaplanılmış olup logaritması ve birinci farkı büyüme olarak yorumlanabilir), M1 (para arzındaki aylık yüzde değişim), Faiz (reel faiz oranları), TÜFE (tüfe endeksindeki aylık yüzde değişim enflasyon olarak yorumlanabilir), Kart (kredi kartı harcamalarının reel tutarı) ile hesaplanılmış VAR modeli matrisi yer almaktadır (Enders, 2014).

\begin{tabular}{|c|c|c|c|c|}
\hline \multirow{2}{*}{ Değişkenler } & \multicolumn{2}{|c|}{ Seviye Değerleri } & \multicolumn{2}{|c|}{ Fark Değerleri } \\
\hline & $\mathrm{ADF}^{\mathrm{a}}$ & $\mathrm{PP}^{\mathrm{a}}$ & $\mathrm{ADF}^{\mathrm{a}}$ & $\mathrm{PP}^{\mathrm{a}}$ \\
\hline Lsanayi & \begin{tabular}{|l}
1.760 \\
$(0.717)$
\end{tabular} & $\begin{array}{l}-2.129 \\
(0.523)\end{array}$ & $\begin{array}{l}-6.168 \\
(0.000)\end{array}$ & $\begin{array}{l}11.133 \\
(0.000)\end{array}$ \\
\hline Lrkart & $\begin{array}{l}1.240 \\
(0.896)\end{array}$ & $\begin{array}{l}1.064 \\
(0.929)\end{array}$ & $\begin{array}{l}10.979 \\
(0.000)\end{array}$ & $\begin{array}{l}11.380 \\
(0.000)\end{array}$ \\
\hline Tüfe & \begin{tabular}{|l|}
9.720 \\
$(0,000)$
\end{tabular} & \begin{tabular}{|l|}
9.682 \\
$(0.000)$
\end{tabular} & & \\
\hline M1 & $\begin{array}{l}9.166 \\
(0.000)\end{array}$ & $\begin{array}{l}14.272 \\
(0.000)\end{array}$ & & \\
\hline Lrfaiz & $\begin{array}{l}2.039 \\
(0,573)\end{array}$ & \begin{tabular}{|l|}
$-2,337$ \\
$(0.410)$
\end{tabular} & \begin{tabular}{|l|l}
9.969 \\
$(0,000)$
\end{tabular} & $\begin{array}{l}-9.998 \\
(0.000)\end{array}$ \\
\hline \multicolumn{5}{|c|}{ Kritik Değerler } \\
\hline$\% 1$ & \multicolumn{2}{|l|}{-4.040} & \multicolumn{2}{|l|}{-4.041} \\
\hline$\% 5$ & \multicolumn{2}{|l|}{-3.449} & \multicolumn{2}{|l|}{-3.450} \\
\hline$\% 10$ & \multicolumn{2}{|l|}{-3.150} & \multicolumn{2}{|l|}{.3150} \\
\hline
\end{tabular}

Tablo: 4

Augmented Dickey-Fuller (ADF), Phillips-Perron (PP) i Durağanlık Testleri 
VAR analizinin ilk aşaması serilerin durağanlığının testidir. VAR analizinde yer alan değişkenler durağan haliyle modelde kullanılır (Sims, 1980). Modelde yer alan değişkenler Augmented Dickey-Fuller (ADF) testi ve Phillips- Perron (PP) ile durağanlık açısından incelenmiştir.

Tablo 4'e göre modelde kullanılacak değişkenlerden reel kredi kartı kullanım tutarı, sanayi üretim endeksi ve faiz oranı, birim kok taşımaktadır yani bu değişkenler düzeyde durağan değildir. Değişkenlerin birinci farkları alınarak durağan hale getirilebilmektedir. Dolayısıyla modelde bu değişkenlerin düzey değerleri ile değil, birinci farkları ile çalışılmıştır. Tüfe ve para arzı değişkenleri, testlere göre durağan oldukları için $\mathrm{I}(0)$ olarak modelde yer alırlar.

VAR analizinde uygun gecikme uzunluğu için (p) AIC, kriterinin gösterdiği 12 gecikme uzunluğu uygun bulunmuştur (Tablo 13).

Tablo: 5

VAR Gecikme Uzunluğu Belirleme Kriteri

\begin{tabular}{|c|c|c|c|c|c|c|}
\hline Gecikme & LogL & LR & FPE & AIC & SC & HQ \\
\hline & & & & & & \\
\hline 0 & 262.3908 & NA & $4.42 \mathrm{e}-09^{*}$ & -5.046879 & $-4.918204^{*}$ & $-4.994774^{*}$ \\
\hline 1 & 283.9598 & 40.60044 & $4.73 \mathrm{e}-09$ & -4.979604 & -4.207553 & -4.666975 \\
\hline 2 & 302.6116 & 33.28066 & $5.38 \mathrm{e}-09$ & -4.855130 & -3.439703 & -4.281975 \\
\hline 3 & 324.8042 & 37.42287 & $5.74 \mathrm{e}-09$ & -4.800083 & -2.741281 & -3.966404 \\
\hline 4 & 347.3353 & 35.78462 & $6.12 \mathrm{e}-09$ & -4.751673 & -2.049495 & -3.657469 \\
\hline 5 & 372.9618 & $38.18856^{*}$ & $6.22 \mathrm{e}-09$ & -4.763958 & -1.418404 & -3.409229 \\
\hline 6 & 387.5240 & 20.27279 & $7.95 \mathrm{e}-09$ & -4.559294 & -0.570364 & -2.944040 \\
\hline 7 & 415.9330 & 36.76462 & $7.90 \mathrm{e}-09$ & -4.626137 & 0.006168 & -2.750359 \\
\hline 8 & 443.7211 & 33.23677 & $8.11 \mathrm{e}-09$ & -4.680806 & 0.594874 & -2.544503 \\
\hline 9 & 469.9662 & 28.81808 & $8.83 \mathrm{e}-09$ & -4.705219 & 1.213838 & -2.308391 \\
\hline 10 & 497.0904 & 27.12426 & $9.78 \mathrm{e}-09$ & -4.746871 & 1.815561 & -2.089518 \\
\hline 11 & 530.7875 & 30.39340 & $9.93 \mathrm{e}-09$ & -4.917401 & 2.288407 & -1.999524 \\
\hline 12 & 567.8606 & 29.80393 & $9.98 \mathrm{e}-09$ & $-5.154130 *$ & 2.695053 & -1.975728 \\
\hline * indicates lag order selected by the criterion \\
LR: sequential modified LR test statistic (each test at 5\% level) & & \\
FPE: Final prediction error \\
AIC: Akaike information criterion \\
SC: Schwarz information criterio \\
HQ: Hannan-Quinn information criterion \\
H.
\end{tabular}

Hesaplanan VAR modelinin bütün olarak durağanlığı ise, modelden elde edilen karakteristik polinomunun ters köklerine bakılarak anlaşılabilir Bütün kökler birim çemberin içinde yer alıyorsa ve modulus tablosunda değerler 1'den küçükse VAR süreci durağandır (Lütkepohl, 1991). 
Şekil: 5

VAR Modeli Durağanlık Grafiği

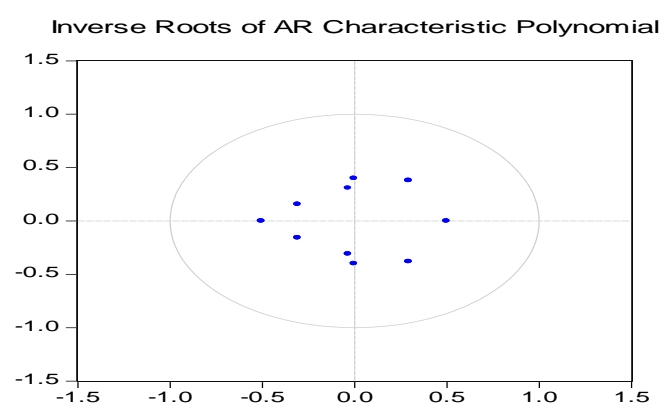

Grafiğe göre AR Karakteristik polinomunun ters kökleri birim çemberin içinde yer almaktadır. Bu durumda VAR modeli durağandır. Diğer taraftan durağanlığın testinde yapısal sorunların varlığını inceleyen Seri korelasyon LM testinin uygulanması Tablo 6' da gösterilmektedir.

Tablo: 6

VAR Hata Kalıntıları Seri Korelasyon LM Testi

\begin{tabular}{|c|c|c|}
\hline Gecikme & LM-istatistiğ $\mathrm{i}$ & olas1lık \\
\hline 1 & 20.09916 & 0.7416 \\
\hline 2 & 23.20198 & 0.5658 \\
\hline 3 & 26.05070 & 0.4049 \\
\hline 4 & 35.70246 & 0.0762 \\
\hline 5 & 23.05059 & 0.5746 \\
\hline 6 & 22.04126 & 0.6334 \\
\hline 7 & 29.51586 & 0.2429 \\
\hline 8 & 30.42469 & 0.2088 \\
\hline 9 & 15.96980 & 0.9157 \\
\hline 10 & 22.03715 & 0.6336 \\
\hline 11 & 31.13461 & 0.1846 \\
\hline 12 & 30.93536 & 0.1912 \\
\hline
\end{tabular}

LM testinde boş hipotez, $\mathrm{H}_{0}: \mathrm{h}$ dereceden gecikmede seri korelasyonun bulunmadığını belirtmektedir. Hata yapma olasılığın $\% 5$ anlamlılık düzeyinden büyük olması durumunda $\mathrm{H}_{0}$ hipotezini kabul etmek zorunda olduğumuzdan $\mathrm{H}_{0}$ hipotezini yani hata terimlerinin arasında otokorelasyonun bulunmadığını kabul ederiz. Tablo 6' ya göre tüm gecikmeler için otokorelasyon bulunmamaktadır. 


\section{Etki Tepki Fonksiyonları ve Varyans Ayrıştırması}

Bir makroekonomik parametrenin üzerinde en etkili değişkenin hangisi olduğu varyans ayrıştırması ile etkili bulunan bu değişkenin politika aracı olarak kullanılabilir olup olmadığı ise etki-tepki fonksiyonları ile belirlenmektedir (Özgen \& Güloğlu, 2004: 97). Etki tepki analizi ile denklemlerdeki hata terimlerinde bir standart sapmalık sarsıntılar yaratılır ve değişkenlerin tepkilerinin zaman içindeki değişimi bulunarak grafik üzerinde incelenir. Etki-tepki analizi bir değişkende meydana gelecek rastgele bir şokun sistemdeki diğer değişkenler üzerindeki etkisini analiz ederken, ekonomik politikalara yön vermede önemli bir rol üstlenmektedir (Özgen \& Güloğlu, 2004: 96).

$\mathrm{Bu}$ çalışmada etki-tepki fonksiyonlarının standart hatalarının hesaplanmasında Monte Carlo tekniği kullanılmaktadır. Eviews 8 programı etki-tepki fonksiyonlarının standart hatalarının hesaplanmasında None, Analytic ve Monte Carlo teknikleri gibi üç farklı seçenek sunmaktadır. Monte Carlo seçeneğinin seçilmesi sonucunda standart hataların yaratacağı şok yinelenmesinin belirlenme imkânı bulunmaktadır.

Etki - tepki analizinde Choleski ayrıştırması matris için kısıtlama koyar ve k (kısıt sayıs1) kadar yapısal şokun tam belirlenmesine (ayırt edilmesine) olanak verir. Bu yöntem ile denklemlerdeki hata terimlerinde bir ölçümlü sapmalık sarsıntılar yaratılır ve değişkenlerin tepkilerinin zaman içindeki değişimi bulunarak grafik üzerinde incelenir. İndirgenmiş form hata terimleri arasında eş dönemli ilişki varsa yani $\Omega$ matrisi köşegen değilse o zaman bir şoku etkisi diğerinden ayırt edilemeyecektir. Bu yüzden etki-tepki fonksiyonları hesaplanırken şoklar dikeyleştirilir (orthogonalized) yani ilişkisiz hale getirilir. Bunu yapmanın bir yolu varyans kovaryans matrisinin Cholesky ayrıştırmasını kullanmaktır (Lütkepohl, 1999: 20; Özgen ve Güloğlu, 2004: 97-98).

Şekil 8-12 arasındaki grafiklerde 10 aylık zaman diliminde etki-tepki fonksiyonları gösterilmektedir. Şekil 8'e göre, para arzındaki aylık \% değişimde meydana gelen bir standart sapmalık yapısal şoka reel faizin tepkisi kısa bir süre için, negatif olmuştur. Birinci dönem ortasında tepki pozitife dönerken, şokun etkisi dördüncü dönem itibari ile dengeye ulaşmış ve sönümlemiştir. Reel faizler üzerinde para politikasındaki değişimler, etkisini 4 aydan sonra yitirmektedir. Ancak tüm tepkiler istatistiksel olarak anlam taşımamaktadır. 
Şekil: 8

\section{Reel Faizin Para Arzındaki Değişime Tepkisi}

Response to Cholesky One S.D. Innovations \pm 2 S.E.

Response of DLREELFAIZ to M1

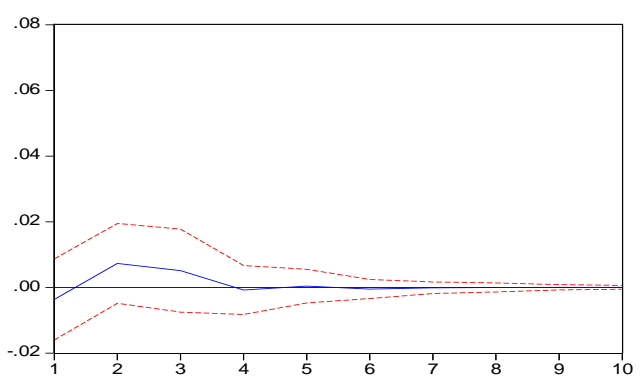

Şekil: 9

TÜFE'nin Para Arzına Tepkisi

Response to Cholesky One S.D. Innovations \pm 2 S.E.

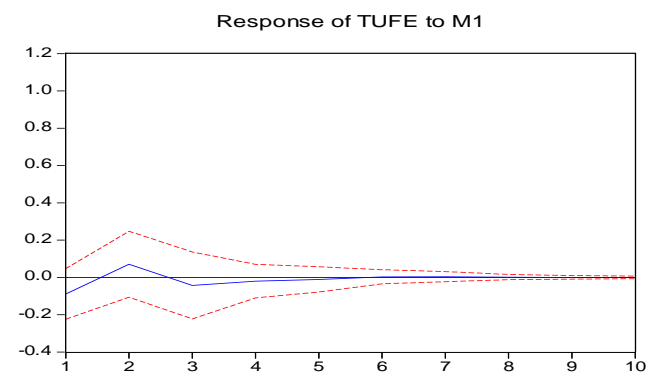

Şekil 9'da yer alan grafik incelendiğinde; para arzında meydana gelen \% değişimdeki bir standart sapmalık yapısal şoka TÜFE'deki değişimin yani enflasyonun tepkisi ikinci döneme kadar negatif olurken ikinci dönemden sonra pozitif tepki yaşanmış, üçüncü dönemde negatif etki tekrar yaşanırken, şokun etkisi altıncı dönem başında sönümlemiştir. Ancak tüm tepkiler istatistiksel olarak anlam taşımamaktadır.

Şekil 10'a göre para arzındaki yüzdesel değişimde meydana gelen bir standart sapmalık yapısal şoka sanayi üretim endeksindeki değişimin yani temsil ettiği ekonomik büyümenin tepkisi çok hafif gerçekleşmiştir ve istatistiksel olarak anlamsızdır. İkinci döneme kadar zayıf pozitif bir tepki şeklinde olurken ikinci dönemden sonra denge değerine 
yaklaşmış ve şokun etkisi sönümlemiştir. Yani para politikasındaki dinamik şokların reel ekonominin önemli göstergesi sanayi üretim endeksindeki değişim yani büyüme üzerinde kayda değer etkisi bulunmamaktadır. Para arzındaki aylık değişimlere verilen şokun reel ekonomi üzerinde önemli bir etki yaratmaması ve denge değerine çabuk ulaşılmasının nedeni artan kredi kartı kullanımının hem ticari hem de tüketim alanında hane halkı ve işletmeleri taksit ya da nakit çekim özelliği ile finanse etmesi olarak yorumlanabilir. Bu şekilde para politikası beklenen etkiyi ekonomi üzerinde göstermeyebilir.

Şekil: 10

\section{Sanayi Üretim Endeksinin Para Arzına Tepkisi}

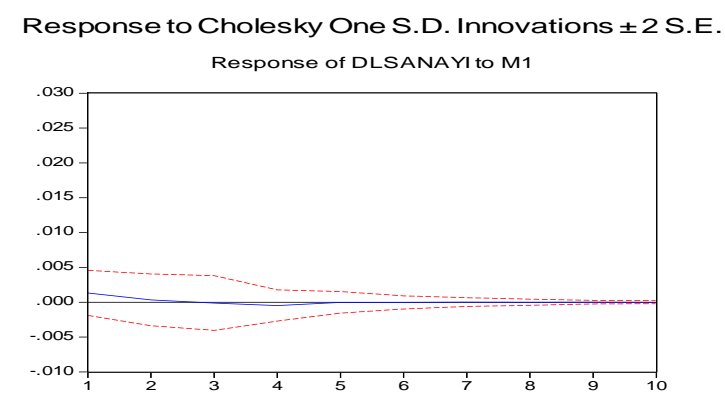

Şekil: 11

Kredi Kartı Kullanımının Para Arzına Tepkisi

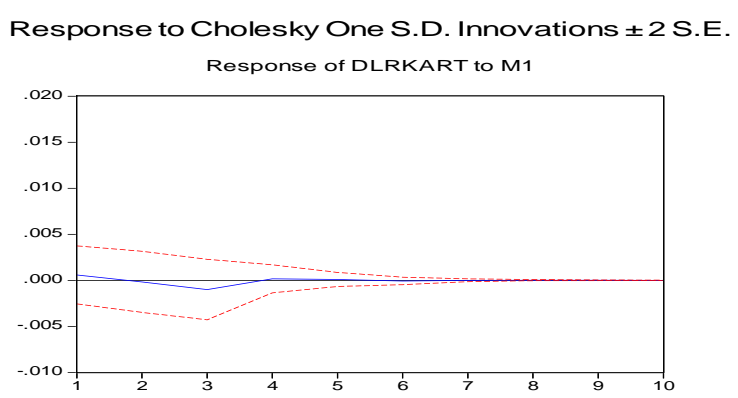

Para arzındaki aylık \% değişimde meydana gelen bir standart sapmalık yapısal şoka kredi kartı kullanım tutarı fazla tepki vermemektedir. İkinci döneme kadar zayıf bir pozitif tepki şeklinde olurken negatif tepki ikinci aydan itibaren başlamış, dördüncü dönem itibari ile denge değerine yaklaşmış ve şokun etkisi sönümlemiştir (Şekil 11). 
Şekil: 12

\title{
Kredi Kartı Kullanımının TÜFE'ye Tepkisi
}

\author{
Response to Cholesky One S.D. Innovations \pm 2 S.E.
}

Response of DLRKART to TUFE

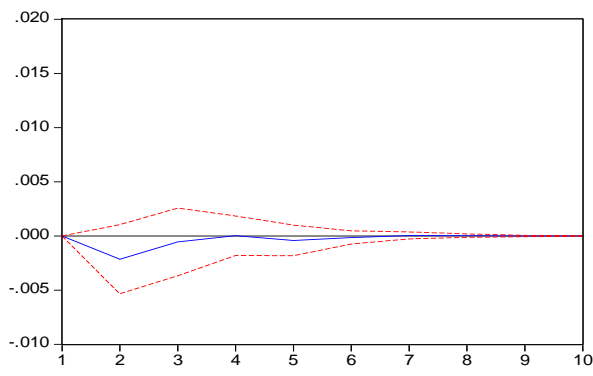

Şekil 12'ye göre TÜFE'deki yüzdesel değişim yani enflasyonda meydana gelen bir standart sapmalık yapısal şoka kredi kartı kullanım tutarı üç döneme kadar negatif tepki verirken dördüncü dönem itibari ile şokun etkisi hafiflemiş ve denge değerine ulaşılmıştır. Tepkiler istatistiksel olarak anlamsızdır.

Varyans ayrıştırması ile modeldeki herhangi bir değişkenin üzerinde diğer değişkenlerden en çok hangisinin etkili olduğu sorusuna cevap aranacaktır. Kurduğumuz VAR modelindeki değişkenlerin varyans ayrıştırması sonuçları aşağıdaki tablolarda verilmiştir.

Tablo: 7

Para Arzının (M1) Varyans Ayrıştırması

\begin{tabular}{|c|c|c|c|c|c|c|}
\hline Dönem & S.H & M1 & DLKART & DLSANAYİ & DLREELFAİZ & TUFE \\
\hline 1 & 7.373635 & 100.0000 & 0.000000 & 0.000000 & 0.000000 & 0.000000 \\
\hline 2 & 7.665948 & 99.22076 & 0.107091 & 0.195730 & 0.451367 & 0.025053 \\
\hline 3 & 7.686177 & 99.12328 & 0.106553 & 0.228684 & 0.512305 & 0.029174 \\
\hline 4 & 7.687468 & 99.11602 & 0.106716 & 0.231426 & 0.515764 & 0.030077 \\
\hline 5 & 7.687551 & 99.11559 & 0.106746 & 0.231619 & 0.515943 & 0.030101 \\
\hline 6 & 7.687556 & 99.11556 & 0.106748 & 0.231630 & 0.515955 & 0.030105 \\
\hline 7 & 7.687557 & 99.11556 & 0.106748 & 0.231631 & 0.515955 & 0.030105 \\
\hline 8 & 7.687557 & 99.11556 & 0.106748 & 0.231631 & 0.515955 & 0.030105 \\
\hline 9 & 7.687557 & 99.11556 & 0.106748 & 0.231631 & 0.515955 & 0.030105 \\
\hline 10 & 7.687557 & 99.11556 & 0.106748 & 0.231631 & 0.515955 & 0.030105 \\
\hline
\end{tabular}


Tablo 7' deki sonuçlara göre, M1'in kısa dönem için (dönem 1) öngörü hata varyansı içinde en büyük paya sahip değişken, ilk dönem yaklaşık tamamı ile kendisi iken zaman içinde uzun vadede etki fazla değişmemiştir. M1'in gelecek dönemler için öngörü hata varyansı içinde en büyük paya sahip değişken yine kendisidir. Bunun en önemli nedeni para arzındaki değişmelerin Merkez Bankası tarafından belirlenmesi ve analizde yer almayan döviz kurlarındaki gelişmeler ve uygulanan para politikasının karakteristiğine göre ayarlanmasidir.

Tablo: 8

Kredi Kartı Kullanım Tutarının Varyans Ayrıştırması

\begin{tabular}{|c|c|c|c|c|c|c|}
\hline & S.E. & M1 & DLRKART & DLSANAYI & DLREELFAIZ & TUFE \\
\hline & & & & & & \\
\hline 1 & 0.016714 & 0.187090 & 99.81291 & 0.000000 & 0.000000 & 0.000000 \\
\hline 2 & 0.016955 & 0.188491 & 97.01030 & 0.063872 & 1.482424 & 1.254909 \\
\hline 3 & 0.016977 & 0.226232 & 96.76155 & 0.064252 & 1.479184 & 1.468780 \\
\hline 4 & 0.016978 & 0.226426 & 96.74830 & 0.064848 & 1.479616 & 1.480811 \\
\hline 5 & 0.016978 & 0.226564 & 96.74758 & 0.064928 & 1.479611 & 1.481312 \\
\hline 6 & 0.016978 & 0.226566 & 96.74756 & 0.064929 & 1.479618 & 1.481332 \\
\hline 7 & 0.016978 & 0.226566 & 96.74756 & 0.064929 & 1.479618 & 1.481332 \\
\hline 8 & 0.016978 & 0.226566 & 96.74756 & 0.064929 & 1.479618 & 1.481332 \\
\hline 9 & 0.016978 & 0.226566 & 96.74756 & 0.064929 & 1.479618 & 1.481332 \\
\hline 10 & 0.016978 & 0.226566 & 96.74756 & 0.064929 & 1.479618 & 1.481332 \\
\hline
\end{tabular}

Tablo 8'e göre, kredi kartı kullanım tutarının kısa vadede (dönem 1) öngörü hata varyansı içinde en büyük paya sahip değişken, kendisidir. Zaman içinde etki çok az değişmiştir. Kredi kartı kullanım tutarının kendinden başka gelecek dönemler için öngörü hata varyansı içinde en büyük paya sahip değişken yaklaşık \%1,48 (10. dönem) ile TUFE ve \%1.47 ile reel faiz iken; M1 ve Sanayi üretim endeksi düşük paya sahiptir. Reel faiz değişkeni olarak kullanılan ihtiyaç kredisi faizlerindeki değişmeler bankaların kredi kartlarında uyguladıkları aylık gecikme faizi için gösterge niteliğindedir. Kredi kartı harcama tutarının gelecek dönemdeki değerini reel faiz oranının açıklama düzeyi \%1,47 ile düşük seviyede olsa da diğer değişkenlere nazaran daha yüksektir. Yine genel fiyatlar düzeyindeki değişmelerde kredi kartı harcama tutarını uzun dönemde açıklama düzeyi \%1.48 gibi düşük bir düzeyde olsa da diğer değişkenlere göre daha yüksek açıklama payına sahiptir.

Tablo 9'a göre, sanayi üretim endeksinin kısa dönemde öngörü hata varyansı içinde en büyük paya sahip değişken, kendisidir. Zaman içinde etki değişmiştir. Sanayi üretim endeksinin gelecek dönemler için (uzun dönem) öngörü hata varyansı içinde en büyük paya sahip değişken (kendisi hariç) \%3.96 (10. dönem) ile kredi kartı kullanımı ve \%1.76 ile reel faiz iken M1 ve TÜFE düşük paya sahiptir. Bu durumda modelde yer alan 
değişkenler içinde sanayi üretim endeksinin açıklamada en önemli değişkenin kredi kartı kullanım tutarı olduğu görülmektedir. Bunun nedeni hane halklarının ve işletmelerin kredi kartlarının yarattığı borçlanma imkânı ile toplam tüketim ve yatırımlarını artırabilmektedirler. Bu da ülke ekonomisinde çarpan ve çoğaltan etkilerine neden olarak topla üretimi artırabilir.

Tablo: 9

Sanayi Üretim Endeksinin Varyans Ayrıştırması

\begin{tabular}{|c|c|c|c|c|c|c|}
\hline & S.E. & M1 & DLRKART & DLSANAYI & DLREELFAIZ & TUFE \\
\hline & & & & & & 0.000000 \\
\hline 1 & 0.018244 & 0.512621 & 0.419729 & 99.06765 & 0.000000 \\
\hline 2 & 0.018811 & 0.484130 & 3.978234 & 93.42697 & 1.736793 & 0.373874 \\
\hline 3 & 0.018848 & 0.495434 & 3.969465 & 93.06055 & 1.768929 & 0.705627 \\
\hline 4 & 0.018851 & 0.496224 & 3.968853 & 93.03246 & 1.768992 & 0.733473 \\
\hline 5 & 0.018851 & 0.496234 & 3.968791 & 93.03108 & 1.769001 & 0.734894 \\
\hline 6 & 0.018851 & 0.496237 & 3.968788 & 93.03102 & 1.769005 & 0.734952 \\
\hline 7 & 0.018851 & 0.496237 & 3.968788 & 93.03102 & 1.769005 & 0.734953 \\
\hline 8 & 0.018851 & 0.496237 & 3.968788 & 93.03102 & 1.769005 & 0.734953 \\
\hline 9 & 0.018851 & 0.496237 & 3.968788 & 93.03102 & 1.769005 & 0.734953 \\
\hline 10 & 0.018851 & 0.496237 & 3.968788 & 93.03102 & 1.769005 & 0.734953 \\
\hline
\end{tabular}

\section{Sonuç}

Hükümetler ve Merkez Bankaları tarafından yürütülen para politikalarının reel ekonomiyi hangi boyutlarda ve hangi kanallarla etkilediğini inceleyen parasal aktarım mekanizmasına değinilen çalışmada, 2005-2014 yılları, Bankalararası Kart Merkezi (BKM), TUIKK ve TCMB verilerinden yararlanılmıştır. Literatür incelemesi sonucunda, parasal aktarım mekanizmasının işleyişini, yani para arzı ile reel değişkenlerin kısa ve uzun vadeli ilşkilerini açıklamada en çok kullanılan yöntem olan VAR analizi kullanılmıştır.

Para politikasındaki dinamik şokların reel ekonominin önemli göstergesi sanayi üretim endeksi üzerinde kayda değer etkisi bulunmamaktadır. Para arzındaki aylık değişimlere verilen şokun reel ekonomi üzerinde önemli bir etki yaratmaması ve denge değerine çabuk ulaşılmasının nedeni artan kredi kartı kullanımının hem ticari hem de tüketim alanında hane halkı ve işletmeleri taksit ya da nakit çekim özelliği ile finanse etmesidir. Bu şekilde para politikası beklenen etkiyi ekonomi üzerinde göstermeyebilir ve para politikasının etkinliği zayıflayabilir.

Çalışmanın diğer önemli bulgusuna göre; sanayi üretim endeksinin gelecek dönemler için açıklanmasında modelde yer alan değişkenler içinde en büyük paya sahip değişkenin, kredi kartı kullanım tutarı olduğu görülmektedir. Bunun nedeni hane halklarının 
ve işletmelerin kredi kartlarının yarattığı borçlanma imkânı ile toplam tüketim ve yatırımlarını artırabilmeleridir. Bu da ülke ekonomisinde çarpan ve çoğaltan etkilerine neden olarak toplam üretimi artırabilir.

\section{Kaynakça}

Banka Kartları ve Kredi Kartları Hakkında Yönetmelik (2014), T.C. Resmî Gazete, 8999, 13 Mayıs 2014

Bankalararası Kart Merkezi (BKM), Aylık Bülten, 2014 Temmuz, <http://www.bkm.com.tr/Upload/basin/BKM-Aylik-Bulten-201406.pdf〉, 03.09.2014.

Bankalararası Kart Merkezi (BKM), 2013 Faaliyet Raporu, <http://www.bkm.com.tr/basin/FaaliyetRaporu-2013.pdf>, 03.09.2014.

Bernanke, B.S. \& A. Blinder (1992), "The Federal Funds Rate and the Channels of Monetary Transnission," American Economic Review, 82 (4), 901-921.

Bernanke, B.S. \& M. Gertler (1995), "Inside the Black Box: The Credit Channel of Monetary Policy Transmission”, The Journal of Economic Perspectives, 9(4), 27-48.

Çevik, S. \& K. Teksöz (2012), Lost in Transmission? The Effectiveness of Monetary Policy Transmission Channels in the GCC Countries, Washington DC, USA: International Monetary Fund.

Enders, W. (2014), Applied Econometric Time Series, 4th Edition, Wiley, USA.

Mishkin, F.S. (1996), "The Channels of Monetary Transmission: Lessons for Monetary Policy", National Bureau of Economic Research, Working Paper: 5464.

Karpuz, E. (2012), “Ödeme Sistemleri ve Araçlarının Artan Kullanımı: Kredi Kartı Kullanımının Para Politikası Etkinliğine Etkisi”, TCMB Uzmanlık Yeterlilik Tezi, Ankara.

Lütkepohl, H. (1991), Introduction to Multiple Time Series Analysis, New York: Springer-Verlag.

Lütkepohl, H. (1999), "Vector Aautoregressions", Discussion Papers, University of Berlin, Interdisciplinary Research Project 373: Quantification and Simulation of Economic Processes.

Lütkepohl, H. \& P. Phillips (2004), Applied Time Series Econometrics, Cambridge University Presss, İngiltere.

Sims, C.A. (1980), "Macroeconomics and Reality", Econometrica, 48, 1-48.

Mitchell, J., \& S. Solomos \& W. Martin (2012), "Monthly GDP estimates for inter-war Britain", Explorations in Economic History, Elsevier, 49(4), 543-556.

Özgen, F.B. \& B. Güloğlu (2004), “Türkiye'de İç Borçların İktisadi Etkilerinin VAR Tekniğiyle Analizi”, METU Studies in Development, (31), 93-114.

Poddar, T. \& K. Hasmik \& S. Randa (2006), "The Monetary Transmission Mechanism in Jordan”, IMF Working Papers, 6-48. 